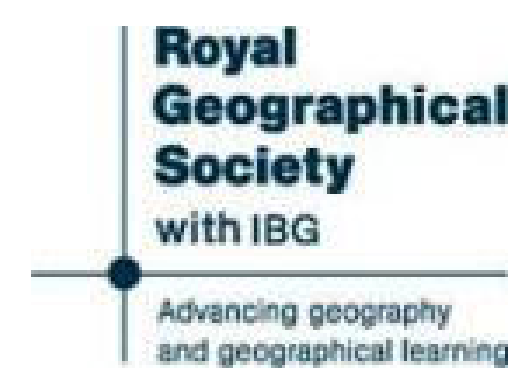

The Shore of Demerara and Essequibo, British Guiana Author(s): Frank J. Gray

Source: The Geographical Journal, Vol. 20, No. 4 (Oct., 1902), pp. 408-411

Published by: The Royal Geographical Society (with the Institute of British Geographers)

Stable URL: http://www.jstor.org/stable/1775565

Accessed: 16/01/2015 17:45

Your use of the JSTOR archive indicates your acceptance of the Terms \& Conditions of Use, available at

http://www.jstor.org/page/info/about/policies/terms.jsp

JSTOR is a not-for-profit service that helps scholars, researchers, and students discover, use, and build upon a wide range of content in a trusted digital archive. We use information technology and tools to increase productivity and facilitate new forms of scholarship. For more information about JSTOR, please contact support@ jstor.org. 
attached to the deep-sea plankton. Hauls with large nets $(10.5$ and 3 feet diameter), from 1000 to 1500 fathoms depth gave rich collections of bathyplanktonic animals--fishes, medusæ, crustaceans, etc.

It is remarkable that no antarctic icebergs were seen during the whole expedition to South Georgia.

Port Stanley, on board the Antarctic, July, 1902.

\section{THE SHORE OF DEMERARA AND ESSEQUIBO, BRITISH GUIANA.}

By FRANK J. GRAY.

ThE shore of Demerara and Essequibo consists principally of "sling mud" with small deposits of "caddy" and broken shell above highwater mark. The only exceptions to this are the sandy shores which lie in front of Golden Fleece and other plantations adjoining the mouths of the rivers. The subsoil is the clay of the country. The "sling mud"

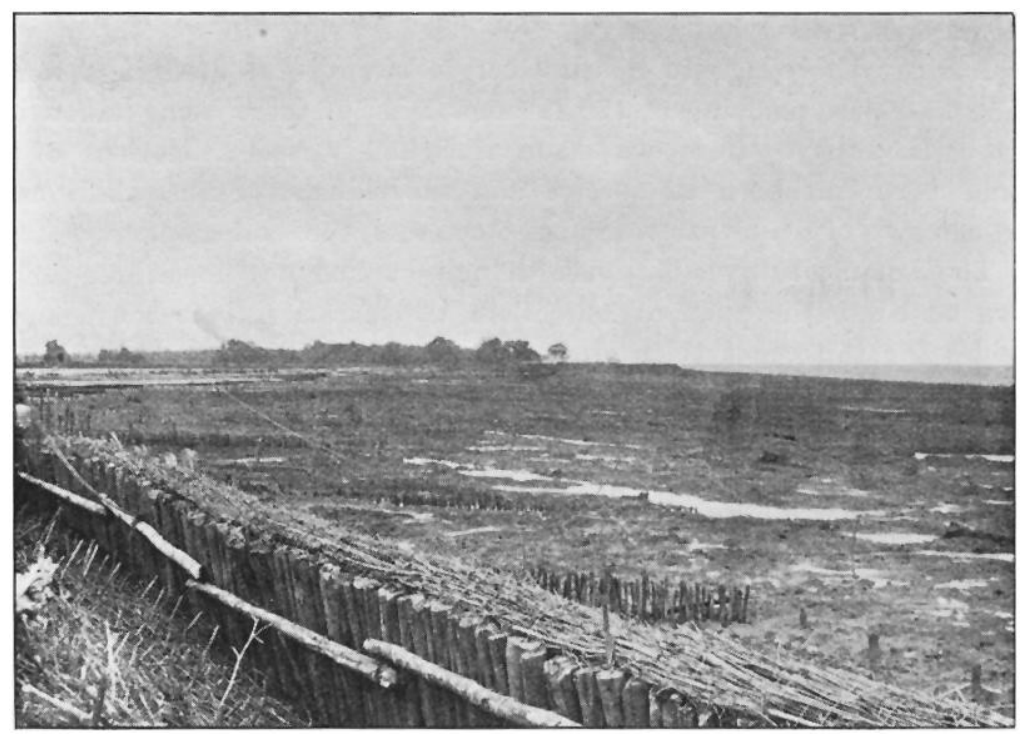

BEA DEFENCES AT PLANTATION hope, Demerara.

is a non-calcareous plastic clay, similar in composition to the subsoil, but containing an excess of sand. It appears to be derived from the subsoil clay by the process of erosion and attrition by the waves, and by the addition of the sand of the "caddy" held in suspension by the sea.

The "caddy" consists of fine sand, mixed with clay and calcareous 
THE SHORE OF DEMERARA AND ESSEQUIBO, BRITISH GUIANA. 409

matter. It differs $\epsilon$ ssentially in composition from the "sling mud," and therefore is not of the same origin. It appears to be derived by erosion from the subsoil of the land immediately adjacent to the shore.

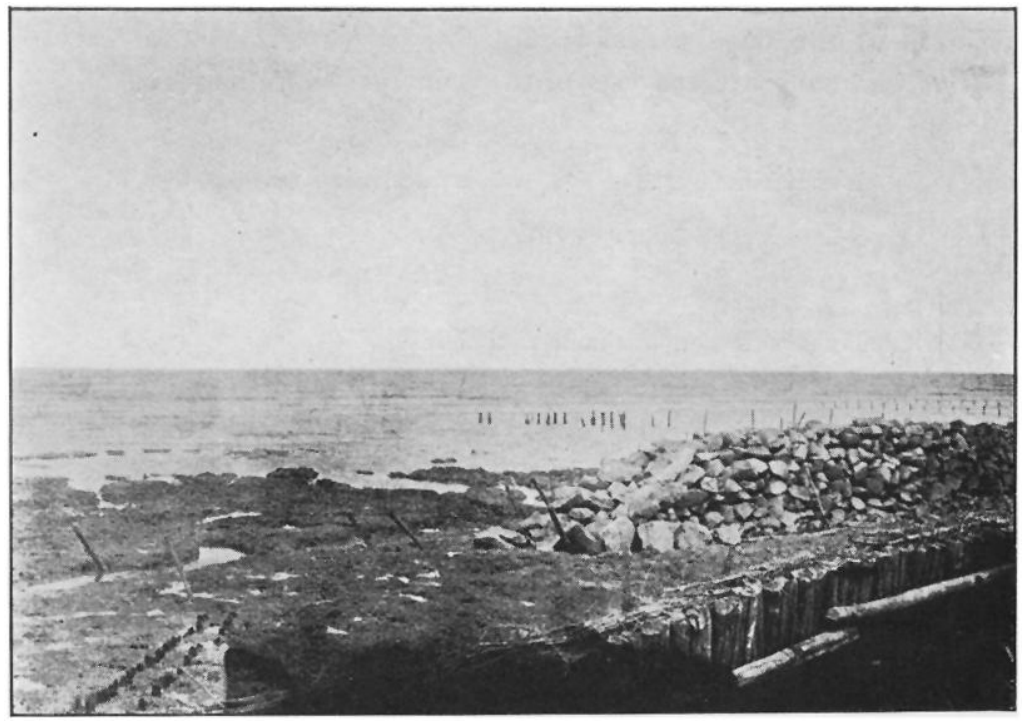

SEA DEFENCES AT PIANTATION HOPE, DEMERARA.

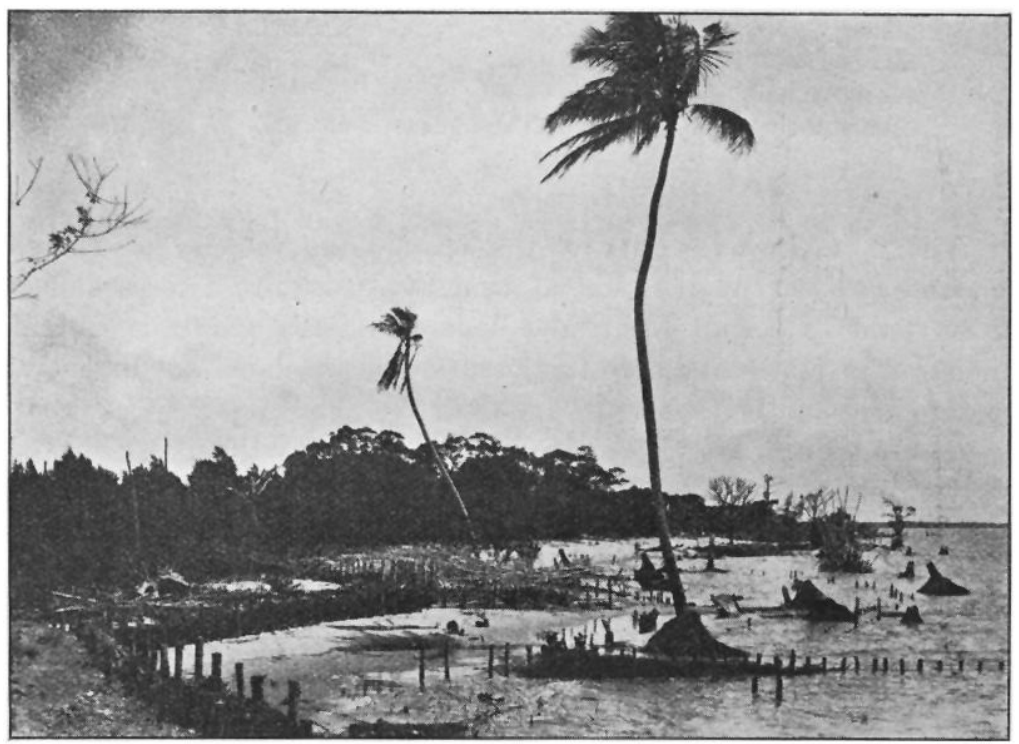

ENCROACHING SEA AT PLANTATION CULlen, ESSEQUibo. 
The sand of the Golden Fleece and other shores which adjoin the rivers, is much coarser than the "caddy" sand. It appears to be derived from the material brought down by the rivers, for it is identical with the material deposited on their banks. It is noticeable that the river Essequibo spreads clear fresh water over the surface of the sea for a radius of about 2 miles.

The following are analyses of the principal shore materials :-

Dried Sumple of Subsoil Clay.

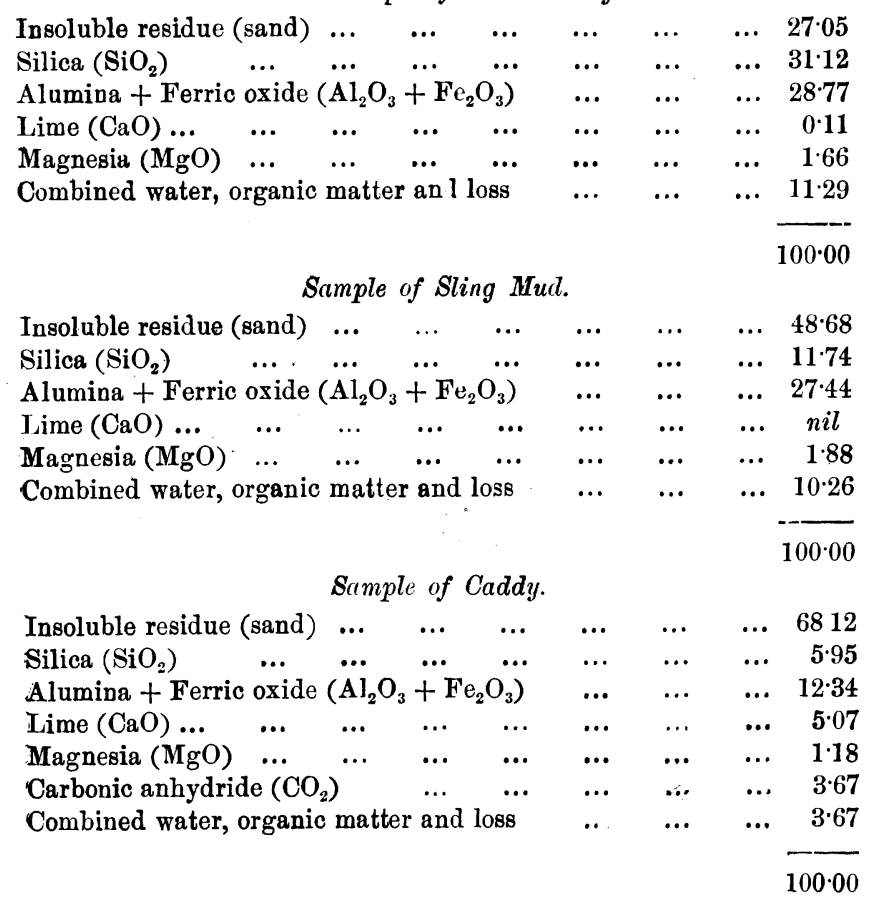

The normal wave-action of the sea and the velocity of the tidal currents are very slight; but at times they acquire a force sufficient to move the extremely light mud in large masses, and thus to denude the shore in places. Where this occurs, the sea dams are liable to be uudermined and breachel.

The sea dams are clay embankments, built for the purpose of preventing inundation by the sea. To prevent abrasion they are, in some cases, faced with bush faggots, held down by spars; in other cases they are defended from the wash of the waves by a fascine breastwork. Wherever practicable a wide belt of courida bush and trees is left seaward of the dam. Breakwaters, either of bushwork or of pell-mell blocks of stone, are also resorted to. But all these devices appear to be ineffectual as methods of permanent protection, and their maintenance is found to be very costly. On this account, Messrs. Case \& 
Gray, of Westminster, were called in to report for the Colonial Government and the principal landowners in 1890.

It should be mentioned that along part of the sea-front of Golden

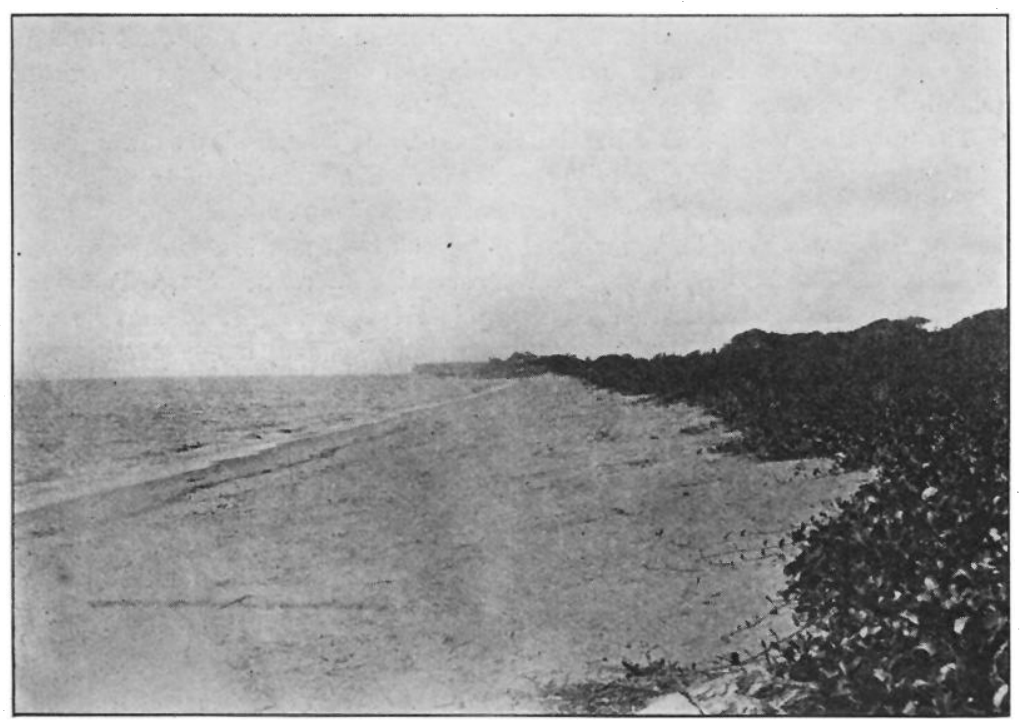

THE SHORE OF PLANTATION GOLDEN FLEECE, ESSEQUIBO.

Fleece, where the sea does not encroach, the full of the shore has been planted with sedge grass to prevent the sand from being blown away, and to preserve the natural barrier against the wash of the waves at high tides.

\section{SOME GEOGRAPHICAL PROBLEMS.**}

By Colonel Sir T. H. HOLDICH, C.B., K.C.I.E., V.P.R.G.S.

The Progress of Geographical Knowledge.-With so large a field as that which is embraced by geography before us, I feel a little doubtful which way to turn in order to gatber into one short space both the scattered records of recent geographical history and to present to you at the same time illustrations of aome fixed principle which, in the course of the development of our geographical knowledge, must govern the progress of it. Last year you heard from Dr. Mill a most excellent summary of the present phase of that development in this country. You heard not only of great activity in the wide world of the unexplored and unknown, but of new efforts to train up a fresh generation of explorers; of new schools springing up amongst us; fresh evidence of the faith that is in us that geographical knowledge points the road to commercial success; happy intimations of the existence of a yet higher

* Presidential Address to the Geographical Section at the Belfast Meeting of the British Association for the Advancement of Science, September 11, 1902. 